\title{
Lepadarq

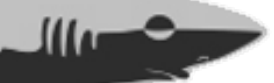

NOVAS INFERÊNCIAS SOBRE O SÍTIO ARQUEOLÓGICO IÇARA-01 A PARTIR DA ANÁLISE DOS REMANESCENTES HUMANOS

NEW INFERENCES ABOUT IÇARA'S CONCHIFEROUS SITE FROM THE HUMAN REMAINS ANALYSIS

Marina Nogueira Di Giusto

Veronica Wesolowski

\section{Como citar este artigo:}

GIUSTO, Marina Nogueira Di; WESOLOWSKI, Verônica. Novas Inferências sobre o Sítio Arqueológico Içara-01 a partir da Análise dos Remanescentes Humanos. In: Cadernos do Lepaarq, v. XVI, n.31., p. 33-52, Jan-Jun. 2019. 


\title{
Novas Inferências sobre o Sítio Arqueológico Içara-01 a partir da Análise dos Remanescentes Humanos
}

\author{
Marina Nogueira Di Giusto ${ }^{a}$ \\ Veronica Wesolowski ${ }^{b}$
}

\begin{abstract}
Resumo: A partir de um projeto de pesquisa que objetivou averiguar o comportamento de marcadores osteológicos em remanescentes humanos na perspectiva da longa duração no litoral sul de Santa Catarina, foram obtidos interessantes resultados para o sítio conchífero Içara-01. Foram analisados os marcadores de estresse osteológicos de Hiperostose Porótica (HP), Cribra orbitalia (CO) e Hipoplasia Linear de Esmalte (HLE) em 35 indivíduos de Içara-01 e seus resultados foram comparados com os adquiridos para indivíduos sepultados em períodos concomitantes dos sambaquis Cabeçuda e Jabuticabeira II. As autoras levantam a hipótese de que os indivíduos sepultados em Içara poderiam ser de um grupo litorâneo que utilizou o sítio como cemitério e que teria mobilidade na costa e no planalto, e não provenientes do planalto e que utilizariam Içara como acampamento temporário, como postula a literatura.
\end{abstract}

\begin{abstract}
As part of a research project that aimed to investigate the osteological markers behavior in human remains from a long-term perspective on the south coast of Santa Catarina (Brazil), interesting results were obtained from the Içara's conchiferous site (Içara-01). The authors analyzed osteological stress markers of Porotic Hyperostosis (HP), Cribra orbitalia (CO) and Linear Enamel Hypoplasia (LEH) in 35 individuals from Içara-01. They compared the results with those obtained for individuals buried in concomitant periods at Cabeçuda and Jabuticabeira II shellmounds. The hypothesis is that the buried individuals in Içara-01 could be members from a coastal group that used the site as a cemetery and had mobility through the coast and the highland, and not that came from the highland and used Içara-01 as a temporary camp, as the literature postulates.
\end{abstract}

\section{Palavras Chave:}

Bioarqueologia; Estilo de Vida; Marcadores de Estresse Osteológicos.

\section{Keywords:}

Bioarchaeology; Lifestyle; Osteological Stress Markers. 


\section{INTRODUÇÃO}

O litoral sul de Santa Catarina, sobretudo ao sul do município de Laguna, possui uma impressiva quantidade de sambaquis, dos pequenos aos monumentais. Desde o século XIX, pesquisadores e projetos de pesquisa têm voltado suas atenções a esses sítios arqueológicos, interessados em entender diversos aspectos dos grupos que os produziram.

Os sambaquis marcam a paisagem inequivocamente; são fartos em vestígios arqueológicos, inclusive sepultamentos, que neles se preservam relativamente bem e, apesar de sofrerem com a exploração comercial no passado e com as pressões turísticas e imobiliárias no presente, resistem graças a seu próprio gigantismo. Assim, de certo modo, sua onipresença e imponência acabaram por quase invisibilizar a pesquisa de registros arqueológicos distintos deles e que poderiam ser mais facilmente destruídos em sua integralidade, ou recobertos pelo asfalto e o concreto da expansão urbana.

Esse mesmo quadro geral também se reflete nas pesquisas de Bioarqueologia que utilizam remanescentes humanos como fonte de estudo para compreender diversos aspectos do modo de vida dos grupos pré-coloniais que ocuparam essa região. Em sua enorme maioria, estudos bioarqueológicos focaram em grandes séries esqueléticas oriundas de sambaquis, dentre as quais se destacam Cabeçuda e Jabuticabeira II, amplamente estudadas (MENDONÇA DE SOUZA, 1995, 1999; RODRIGUES-CARVALHO; MENDONÇA DE SOUZA, 1998; OKUMURA; EGGERS, 2005, 2012; PEZO-LANFRANCO et al, 2018, entre outras).

Uma exceção a este quadro geral é o sítio Içara-01, escavado entre os anos de 1992 e 1995 por uma equipe do Instituto Anchietano de Pesquisas, coordenada pelo arqueólogo Pedro Ignacio Schmitz (SCHMITZ et al, 1999). Entre os vestígios arqueológicos recuperados nas escavações destaca-se uma expressiva série esquelética humana, a única do litoral sul catarinense não relacionada a grupos sambaquieiros, a priori. Essa série, ainda pouco estudada, apresenta condições desejáveis para estudos bioarqueológicos, devido ao seu tamanho razoável e à boa conservação dos esqueletos (SCHMITZ et al, 1999; IZIDRO, 2001; DEMAMMAN, 2004)

As pesquisas bioarqueológicas realizadas nas últimas duas décadas nos litorais norte e central de Santa Catarina incluíram séries esqueléticas oriundas de sambaquis típicos (p.ex. Morro do Ouro, Rio Comprido e Ilha de Espinheiros II), de sambaquis tardios (a partir de 2000 anos AP, no sentido do termo empregado por DeBlasis e colaboradores [2014]), de sambaquis com cerâmica em suas ocupações mais recentes (p.ex. Forte Marechal Luz e Enseada I) e de sítios rasos (p. ex. Armação do Sul $)^{1}$. Estas pesquisas indicaram diversidade sincrônica e diacrônica em aspectos ligados ao processo saúdedoença (como estresse, traumas, patologias dentárias e infecções), que sugerem também uma variabilidade interna na maneira de viver dos grupos que produziram estes registros arqueológicos (WESOLOWSKI; NEVES, 2001). No entanto, para o litoral sul do estado não existiam, até o momento, abordagens semelhantes.

Este artigo apresenta os resultados obtidos na análise da série esquelética de Içara-01 para três marcadores inespecíficos de estresse: Hipoplasias Lineares de Esmalte (HLE), Cribra orbitalia (CO) e Hiperostose Porótica (HP). Estes são uma parte dos resultados da pesquisa de mestrado desenvolvida por uma de nós (MNDG) a qual objetivou entender, em uma perspectiva de longa duração, as variações diacrônicas, intra e inter-sítios nos padrões de estresse observados em séries esqueléticas de sambaquis, de sambaquis tardios e de sítios usualmente considerados acampamentos relacionados a populações vindas do planalto (neste caso Içara-01) do litoral sul-catarinense (GIUSTO, 2017).

Os dados aqui apresentados são provenientes de uma abordagem inédita para esta série esquelética de Içara-01 e cuja discussão pode lançar uma nova perspectiva sobre a natureza da ocupação do sítio. 


\section{BIOARQUEOLOGIA E MARCADORES DE ESTRESSE FISIOLÓGICO}

A Bioarqueologia é uma área de estudo que investiga questões que abrangem os modos de vida das populações humanas a partir da análise de remanescentes de corpos humanos arqueologicamente contextualizados, para compreender como tais grupos viveram. Essa disciplina tem se desenvolvido a partir de uma perspectiva biocultural, na qual as dimensões biológicas e culturais dos corpos humanos são indissociáveis de aspectos como processo saúde-doença, adaptabilidade, natalidade, mortalidade, entre outros. Essa perspectiva articula dados biológicos (estimativas sexual, etária, estatura, patologias, traumas ósseos, etc.), arqueológicos (cultura material, contextos funerários, etc.) e tafonômicos para compreender os modos de vida de populações humanas pretéritas em vários aspectos (BUIKSTRA, 2006; MENDONÇA DE SOUZA, 2014).

Ossos e dentes são formados por tecidos parcialmente mineralizados e preservam-se relativamente bem no registro arqueológico. Os ossos são órgãos vivos, dinâmicos, plásticos, que respondem aos estímulos decorrentes da vida dos indivíduos (tais como traumas, infecções, atividades físicas, déficits nutricionais, entre outros), podendo sofrer alterações em sua morfologia, as quais podem acompanhar o indivíduo ao longo de toda a sua vida (MENDONÇA DE SOUZA, 1995; LUNA, 2006). Os dentes são mais mineralizados que os ossos, mas possuem plasticidade e capacidade regenerativa limitadas (GOODMAN et al., 1980).

Estas duas características, plasticidade em vida e resistência após a morte, fazem do esqueleto excelente material para o estudo e inferência de vários aspectos do modo de vida de grupos do passado.

Entre as alterações ósseas e dentárias mais observadas em remanescentes esqueléticos humanos estão as porosidades presentes na superfície externa do crânio (denominada Hiperostose Porótica [HP]) e na região ântero-superior das órbitas (denominada Cribra orbitalia [CO]) e as linhas de diminuição de espessura do esmalte dentário (denominada Hipoplasia Linear de Esmalte [HLE]). Esses três tipos de alterações são considerados Marcadores Inespecíficos de Estresse (MIE).

Os MIE são alterações ósseas e dentárias que sinalizam a ocorrência de interrupções ou perturbações fisiológicas durante a vida dos indivíduos, sendo provocadas por uma variedade de estressores, patológicos ou não, em geral resultantes da combinação de fatores ambientais, culturais e individuais (MARTIN et al, 1985; MENDONÇA DE SOUZA, 1995, LARSEN, 1997; ARMELAGOS, 2003).

Tanto a HP quanto a CO são alterações que ocorrem devido à expansão da medula hematopoiética e têm sido amplamente relacionadas tanto com a presença de anemias congênitas (talassemia e falciforme) quanto com anemias adquiridas (deficiência de ferro crônica, seja de origem nutricional, infecciosa, parasitária ou metabólica) (ANGEL, 1966; ARMELAGOS, 2003; BRITTON et al., 1960; CARLSON, ARMELAGOS, 1974; EL-NAJJAR, ROBERTSON, 1976; GOODMAN et al., 1984; LARSEN, 1997; MELLO E ALVIM, GOMES, 1989; MENDONÇA DE SOUZA, 1995; MENSFORTH et al., 1978; MOSELEY, 1965; WALKER et al., 1998; STECKEL et al., 2002; STUART-MACADAM, 1985, 1992)

A condição anêmica é caracterizada pela baixa concentração de hemoglobina, uma proteína presente nas hemácias do sangue e responsável pelo transporte de oxigênio (MOREIRA, SILVA, 2014). Sob essa condição, o organismo gera uma resposta fisiológica que leva a produção de mais hemácias na tentativa de superar essa baixa concentração de hemoglobina. As hemácias são produzidas na medula vermelha presente na região trabecular dos ossos, especialmente do crânio, que se expande para produzi-las em maior quantidade, o que muitas vezes é acompanhado pelo afinamento da cortical externa da região atingida. Superada a condição anêmica, a trabecular do osso volta ao seu tamanho normal e as porosidades cicatrizamse (EL-NAJJAR et al, 1975; MELLO e ALVIM, GOMES, 1989; MENSFORTH et al., 1978; MOSELEY, 1965; STUARTMACADAM, 1985, 1992; WALKER, 1986; WALKER et al., 2009; ZUCKERMAN et al., 2014). A figura 1 esquematiza o desenvolvimento da condição anêmica e da formação das porosidades de HP e CO.

As prevalências de HP e CO têm se mostrado particularmente elevadas entre grupos litorâneos, tanto na América do Norte como na do Sul, apesar das evidências arqueológicas indicarem a existência de uma dieta baseada em recursos proteicos ricos em ferro nesses contextos. Embora altas prevalências de HP e CO sejam mais comumente vinculadas às anemias congênitas, essas nunca foram evidenciadas em esqueletos humanos de grupos americanos pré-coloniais, levando a que este tipo de anemia seja desconsiderada para explicar a ocorrência dos marcadores nestas populações. Assim, temse considerado que HP e CO nessas populações costeiras, inclusive as brasileiras, poderiam estar relacionadas a anemias decorrentes de processos infecciosos e parasitários (WALKER, 1986; MELLO e ALVIM, GOMES, 1989; MELLO e ALVIM et al., 1991; MENDONÇA DE SOUZA, 1995, 1999; BLOM et al., 2005; SUBY, 2014). 


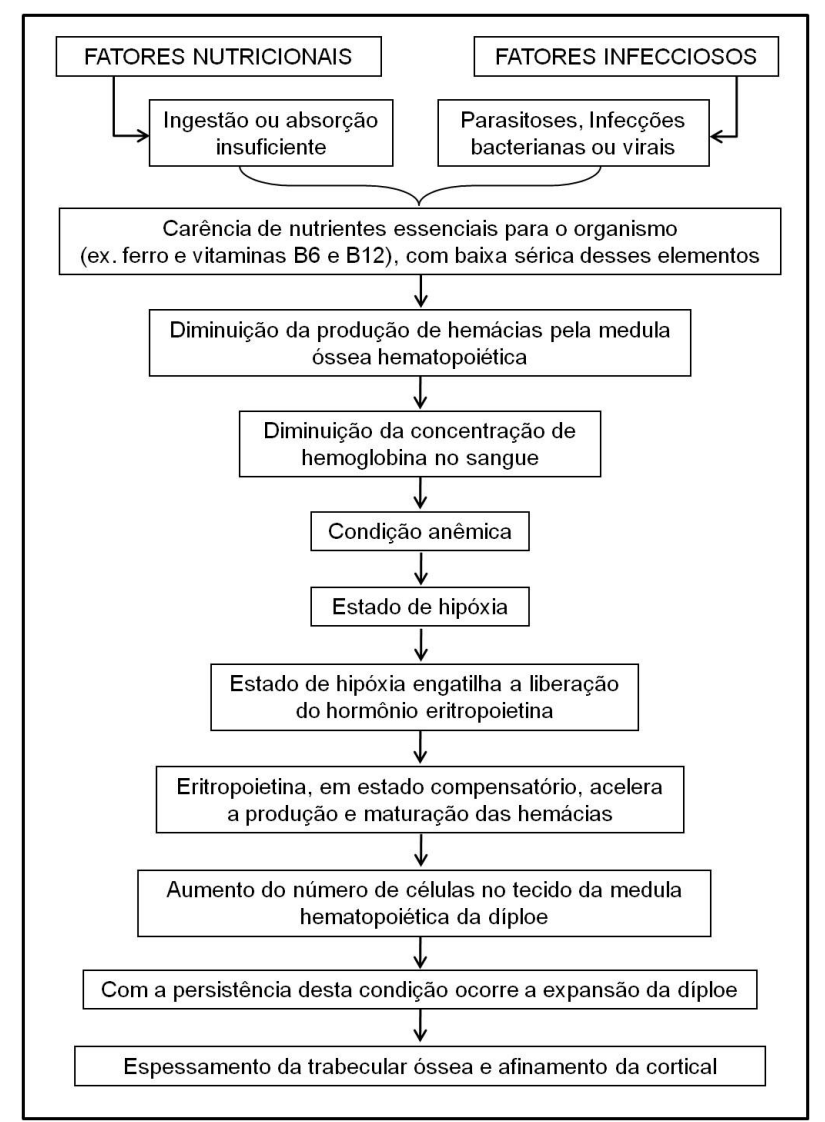

Figura 1: Esquema de desenvolvimento da condição anêmica adquirida e desenvolvimento da HP e CO (Fonte: Giusto, 2017).

Em relação às HLE, essas são observadas como linhas de diminuição na espessura normal do dente, paralelas à superfície oclusal, que se formam quando um evento de estresse sistêmico (aquele que acomete o organismo e não apenas o dente afetado) interrompe a produção de ameloblastos, que são células precursoras do esmalte dentário, durante o período de formação da coroa dentária. Não há relação direta entre a severidade do estresse que ocasionou o distúrbio e a severidade do defeito hipoplásico (GOODMAN et al., 1980, 1984; FISCHER, 2012; HASSETT, 2014). A figura 2 esquematiza o desenvolvimento das HLE nos dentes.

Uma série de elementos fisiológicos, patológicos e nutricionais foi apontada como causas das HLE, entre os quais podem ser citados raquitismo, escorbuto, doenças infecciosas, aspectos nutricionais e processo de desmame (COOK, BUIKSTRA, 1979; HUTCHINSON, LARSEN, 1988; UBELAKER, 1992; WRIGHT, 1997; FISCHER, 2012; PRIMEAU et al., 2015).

A coroa dentária possui um padrão de desenvolvimento, que na dentição decídua (i.e. dentição "de leite") começa em torno do quarto mês intrauterino e completa-se antes do início da erupção do dente, enquanto que na dentição permanente começa logo após o nascimento, estando completo por volta dos dez anos de idade (exceto $3^{\circ}$ molares). Através da posição das linhas de hipoplasia no dente é possível estimar a idade que o indivíduo tinha em vida quando sofreu a paralisação ou diminuição do ritmo da amelogênese ${ }^{2}$ (BUIKSTRA, UBELAKER, 1994; REID, DEAN, 2000; MARTIN et al., 2008; RITZMAN et al., 2008; HASSETT, 2014). A figura 3 ilustra o padrão de desenvolvimento da dentição permanente com intervalos de um ano. 


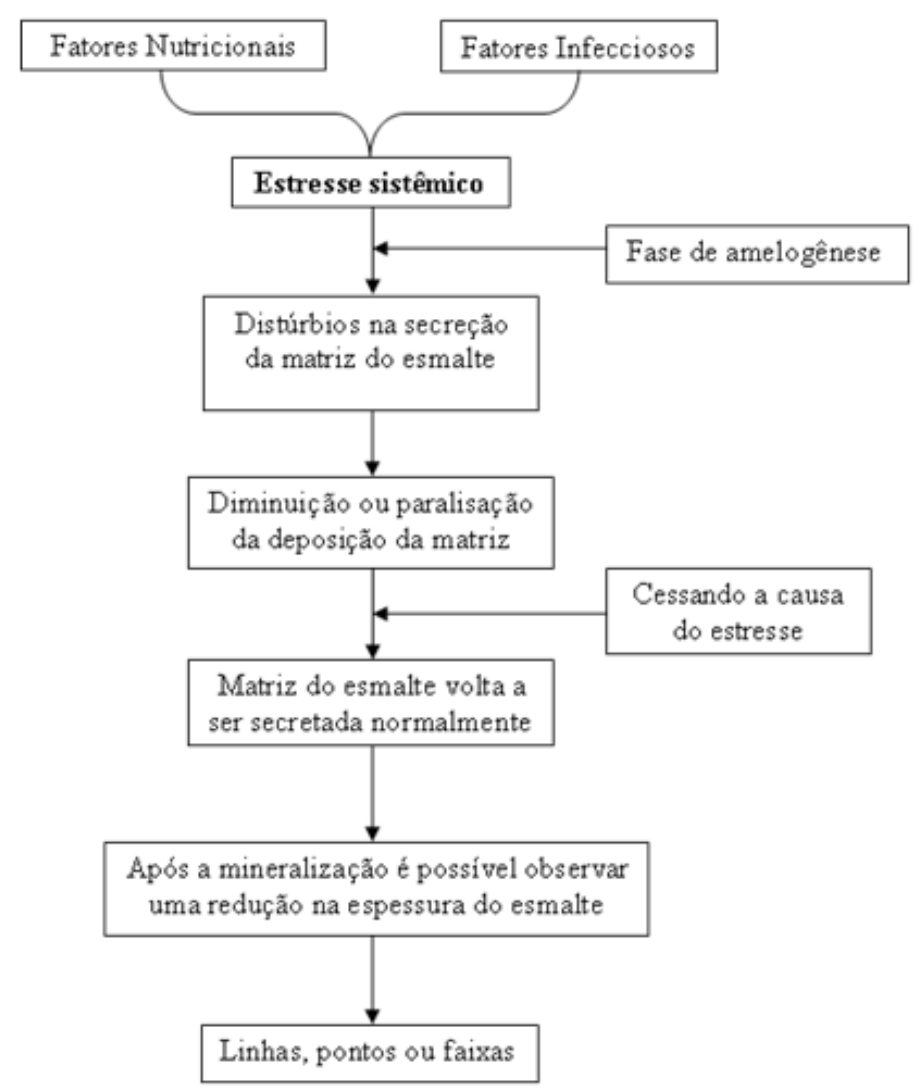

Figura 2: Esquema do desenvolvimento da HLE (Fonte: Giusto, 2017).

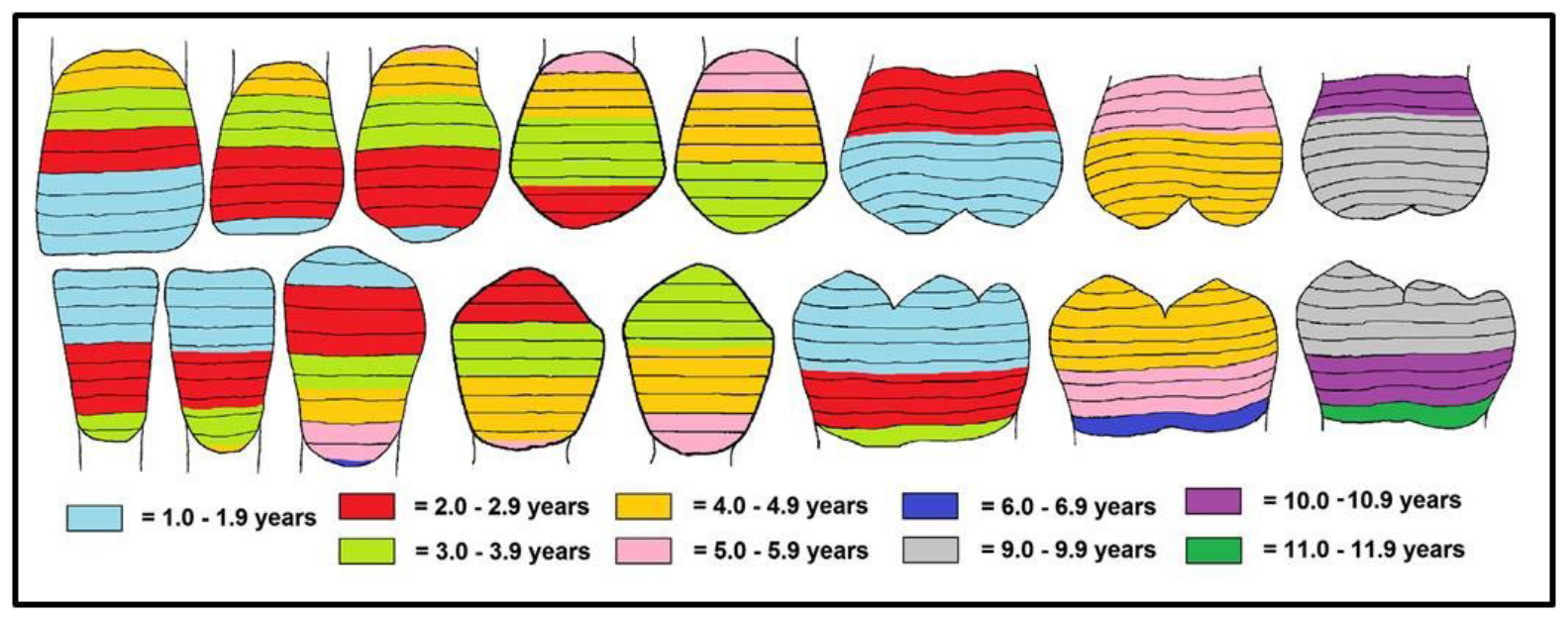

Figura 3: Desenvolvimento da dentição permanente em intervalos de 1 ano (Fonte: Primeau et al., 2015).

\section{O SÍTIO IÇARA-01 E SUA SÉRIE ESQUELÉTICA}

O sítio arqueológico Içara-01 (SC-IÇ-01) está localizado no município de Içara, litoral sul de Santa Catarina, em uma faixa de dunas adjacente à desembocadura do rio Araranguá, distando $1 \mathrm{~km}$ da costa (Figura 4). Com dimensões aproximadas de $300 \mathrm{~m}$ de comprimento por $30 \mathrm{~m}$ de largura, Içara-01 destaca-se na paisagem como um montículo de conchas e tem sido considerado por diversos pesquisadores como um acampamento conchífero (SCHMITZ, 1996, 1998; SCHMITZ et al., 1999; IZIDRO, 2001). Existem duas datações para o sítio, uma obtida em amostras coletadas na área mais periférica, junto ao seu limite leste, de 1630-1530 anos cal AP, e outra obtida em amostra coletada em área mais central do sítio, de 1510-1390 anos 
cal AP (SCHMITZ et al., 1999).

A região na qual Içara está localizado apresenta uma conformação ambiental constituída por campos de dunas, formações lagunares e vegetação de restinga, que estabelece um contínuo com as regiões de Campo Bom, Arroio Correntes e Jaguaruna, mais ao norte. Embora a região de Içara seja menos intensamente estudada do ponto de vista arqueológico, a ocupação pré-colonial parece seguir o mesmo padrão encontrado em regiões mais ao norte, com a presença de sambaquis, de montículos ictiológicos mais rasos sem cerâmica e de sítios Tupi-guarani (SCHMITZ et al., 1999).

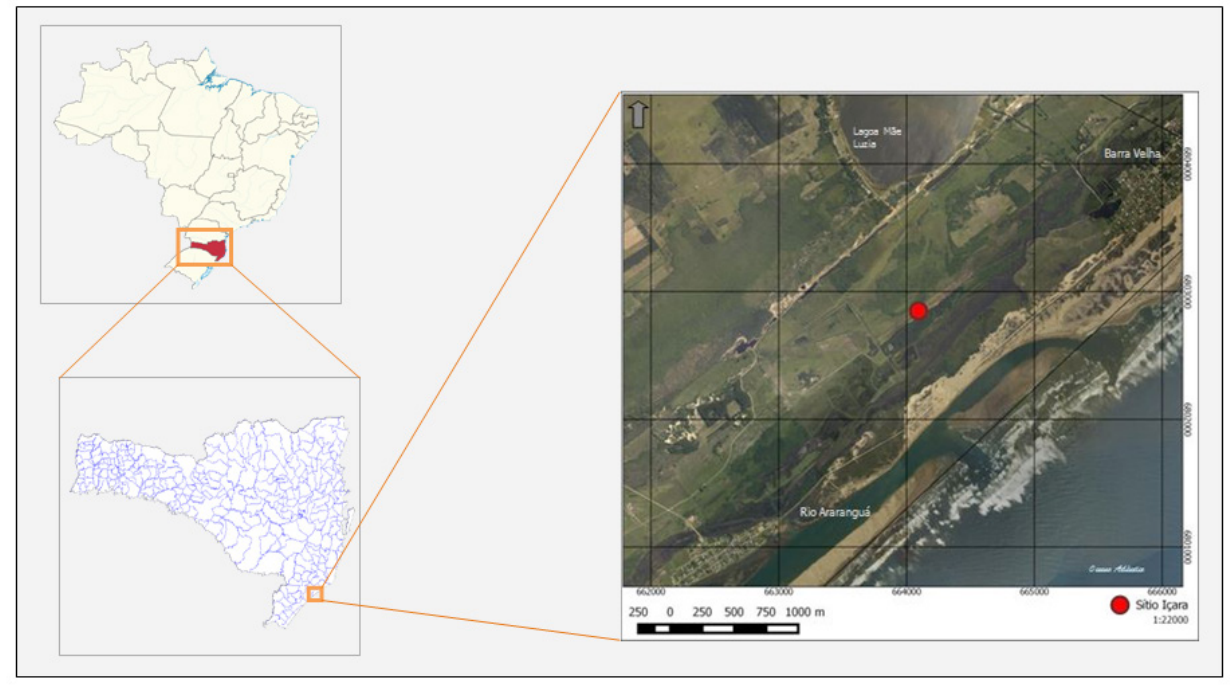

Figura 4: Localização do sítio conchífero Içara

Schmitz e colaboradores (1999) entendem o sítio Içara-01 como um acampamento de verão ocupado por grupos provenientes do planalto, possivelmente antepassados do atual grupo indígena Xokleng, que também o utilizavam como cemitério. Incorporando o litoral sul do estado de Santa Catarina como território, esses grupos teriam em Içara-01 um local de valor ritual voltado para o sepultamento de seus mortos (SCHMITZ, 1996, 1998). Tal hipótese foi construída pelos autores a partir da integração de dados arqueológicos e etnográficos sobre os Xokleng e os Kaingang (SCHMITZ, 1996).

Dentre os vestígios zooarqueológicos presentes no sítio há uma grande quantidade de ossos de bagre (que sobem o rio Araranguá no verão), indicando a exploração majoritária de peixes marinhos, com ausência de vestígios de fauna invernal (SCHMITZ et al., 1999). Também foram identificados em menor quantidade moluscos, mamíferos terrestres, aves e répteis (ROSA, 2006). Essa composição faunística estabeleceria um contrapondo entre Içara-01 e os sambaquis do litoral sul de Santa Catarina, inclusive o sambaqui de Içara 06 (SC-IÇ-06) localizado próximo, nos quais há uma presença mais expressiva de aves e de mamíferos marinhos que em Içara-01 (ROSA, 2006).

O conjunto de artefatos recuperado pela escavação é bastante exíguo. A cerâmica está completamente ausente, mas foram observados artefatos em ossos e conchas assim como líticos, entre os quais destaca-se a presença de mãos-de-pilão, cuja origem seria o planalto e que estariam relacionadas à preparação de certos alimentos, tal qual o pinhão (SCHMITZ, 1996).

Exceto pelos vestígios faunísticos, os remanescentes esqueléticos humanos constituem os vestígios arqueológicos mais comuns em Içara-01. Durante as escavações dos $364 \mathrm{~m}^{2}$ foram identificadas quatro áreas funerárias que concentravam sepultamentos, tendo sido exumados pelo menos cinquenta e seis (56) indivíduos (GIUSTO, 2017) em trinta e quatro (34) sepultamentos, entre primários, secundários, simples, múltiplos e cremações (SCHMITZ, 1996; SCHMITZ et al., 1999). As áreas funerárias estavam localizadas próximas ao limite do sítio, três delas junto ao limite leste e uma junto ao oeste e, além delas, foram exumados dois sepultamentos isolados na área central do sítio (IZIDRO, 2001). Os diversos modos de sepultar os corpos, assim como a ausência de vestígios que indicariam alguma distinção social no grupo, levam Içara a ser considerado um sítio singular na região (IZIDRO, 2001).

Uma hipótese admitida para explicar essa variedade de tipos de sepultamento propõe que Içara-01 funcionaria como o cemitério preferencial do grupo, de tal maneira que mesmo indivíduos que morreram longe do sítio tinham seus ossos transportados para que tivessem naquele local seu sepultamento final. Assim, os sepultamentos secundários e cremações decorreriam dessa prática, enquanto que os indivíduos que morreram próximo ao sítio durante os períodos sazonais de 
ocupação eram imediatamente nele sepultados, resultando nos sepultamentos arqueologicamente interpretados como primários (SCHMITZ, 1996, 1998; SCHMITZ et al. 1999).

\section{MATERIAL}

A série esquelética humana de Içara-01 está sob guarda do Instituto Anchietano de Pesquisas na UNISINOS (São Leopoldo/RS). Os esqueletos passaram por uma curadoria logo após sua escavação, ocasião em que foi apontada a presença de algumas patologias orais e ósseas e contabilizado o número mínimo de 84 indivíduos (SCHMITZ et al., 1999; IZIDRO, 2001; DEMAMMAN, 2004).

Nesta pesquisa, dos 56 indivíduos que puderam ser efetivamente confirmados e avaliados para estimativas de sexo e idade, foram analisados 35 indivíduos para pelo menos um dos marcadores de interesse (HP, CO, HLE), sendo: 3 lactentes (idade entre 1 mês e 1 ano de idade), 6 crianças na $1^{\text {a }}$ infância (entre 1,1 e 5,9 anos), 2 crianças na $2^{\text {a }}$ infância (entre 6 e 12 anos), 4 jovens (entre 13 e 18 anos), 2 adultos jovens (entre 19 e 25 anos), 4 adultos (entre 26 e 34 anos), 11 adultos maduros (entre 35 e 49 anos), 2 adultos velhos (mais de 50 anos) e 1 adulto com idade indeterminada. Dentre os adultos, 7 são do sexo feminino e 13 do sexo masculino. As análises para estimativa de sexo e idade foram baseadas em manuais específicos (BUIKSTRA, UBELAKER, 1994; SHAEFER et al., 2009).

Para HP, foram analisados todos os indivíduos que possuíam pelo menos 50\% do parietal esquerdo e/ou direito e/ou frontal presentes, perfazendo 23 indivíduos. Para $\mathrm{CO}$, foram analisados todos os indivíduos que possuíam pelo menos $50 \%$ dos tetos das órbitas direita e/ou esquerda presentes, perfazendo 15 indivíduos. Para HLE, foram analisados os indivíduos que possuíam dois ou mais dentes anteriores (permanentes e/ou decíduos), com no mínimo 1/3 da coroa presente e formação do esmalte completa, superiores e/ou inferiores, perfazendo 17 indivíduos (13 indivíduos para a dentição permanente e 4 para dentição decídua). A Tabela 1 indica os indivíduos analisados, suas estimativas de sexo e idade e o marcador de estresse observado.

Tabela 1: Indivíduos analisados em Içara, com indicação do marcador de estresse observado.

\begin{tabular}{|c|c|c|c|c|c|}
\hline SEPULTAMENTO & $\begin{array}{c}\text { ESTIMATIVA } \\
\text { SEXO }\end{array}$ & $\begin{array}{c}\text { ESTIMATIVA } \\
\text { IDADE }\end{array}$ & $\begin{array}{c}\text { ANÁLISE } \\
\text { HLE }\end{array}$ & $\begin{array}{c}\text { ANÁLISE } \\
\text { HP }\end{array}$ & $\begin{array}{c}\text { ANÁLISE } \\
\text { CO }\end{array}$ \\
\hline Sep. 92.2 & Indeterminado & Lactente & $\mathrm{X}$ & - & - \\
\hline Sep. $92.3 \mathrm{a}$ & Feminino & Adulto & $\mathrm{X}$ & $\mathrm{X}$ & - \\
\hline Sep. $92.3 \mathrm{c}$ & Masculino & Adulto Maduro & - & $\mathrm{X}$ & - \\
\hline Sep. $92.3 \mathrm{~d}$ & Indeterminado & $1^{\mathrm{a}}$ Infância & - & - & $\mathrm{X}$ \\
\hline Sep. 93.8 & Indeterminado & Jovem & $\mathrm{X}$ & - & - \\
\hline Sep. 93.9 & Masculino & Adulto Velho & - & $\mathrm{X}$ & - \\
\hline Sep. 93.10 & Feminino & Adulto Maduro & - & $\mathrm{X}$ & - \\
\hline Sep. $94.1 \mathrm{a}$ & Indeterminado & $1^{a}$ Infância & $\mathrm{X}$ & - & - \\
\hline Sep. $94.1 \mathrm{~b}$ & Indeterminado & $1^{\mathrm{a}}$ Infância & $\mathrm{X}$ & - & - \\
\hline Sep. 94.3 & Feminino & Adulto Maduro & - & $\mathrm{X}$ & - \\
\hline Sep. $94.4 \mathrm{a}$ & Masculino & Adulto Ind. & - & $\mathrm{X}$ & $\mathrm{X}$ \\
\hline Sep. 94.5 & Indeterminado & $2^{a}$ Infância & $\mathrm{X}$ & - & - \\
\hline Sep. $94.8 \mathrm{a}$ & Masculino & Adulto & - & $\mathrm{X}$ & - \\
\hline Sep. 94.8 b & Indeterminado & Jovem & - & - & $\mathrm{X}$ \\
\hline Sep. $94.8 \mathrm{c}$ & Indeterminado & $1^{a}$ Infância & - & - & $\mathrm{X}$ \\
\hline Sep. 94.9 & Feminino & Adulto Jovem & $\mathrm{X}$ & $X$ & $X$ \\
\hline Sep. 94.10 & Feminino & Adulto Maduro & - & $X$ & $\mathrm{X}$ \\
\hline Sep. 94.12 & Indeterminado & Jovem & $\mathrm{X}$ & $\mathrm{X}$ & $\mathrm{X}$ \\
\hline Sep. 94.13 & Feminino & Adulto Maduro & $\mathrm{X}$ & $\mathrm{X}$ & $\mathrm{X}$ \\
\hline Sep. $94.14 \mathrm{a}$ & Indeterminado & Jovem & $\mathrm{X}$ & - & - \\
\hline Sep. 94.15 & Masculino & Adulto Jovem & - & $\mathrm{X}$ & $\mathrm{X}$ \\
\hline Sep. $94.16 \mathrm{c}$ & Indeterminado & $1^{\text {a }}$ Infância & $\mathrm{X}$ & - & - \\
\hline Sep. 94.17 & Indeterminado & $2^{\mathrm{a}}$ Infância & $\mathrm{X}$ & - & - \\
\hline Sep. 94.18 & Masculino & Adulto Maduro & $\mathrm{X}$ & $X$ & $X$ \\
\hline Sep. 94.19 c & Ind. & $1^{\mathrm{a}}$ Infância & - & - & $\mathrm{X}$ \\
\hline Sep. 94.20 & Masculino & Adulto Maduro & - & $\mathrm{X}$ & $\mathrm{X}$ \\
\hline Sep. $94.21 \mathrm{a}$ & Masculino & Adulto Velho & - & $\mathrm{X}$ & - \\
\hline
\end{tabular}




\begin{tabular}{|c|c|c|c|c|c|}
\hline Sep. 95.1 & Masculino & Adulto Maduro & $\mathrm{X}$ & $\mathrm{X}$ & - \\
\hline Sep. 95.2 a & Masculino & Adulto Maduro & - & $\mathrm{X}$ & $\mathrm{X}$ \\
\hline Sep. 95.4 a & Feminino & Adulto & $\mathrm{X}$ & $\mathrm{X}$ & - \\
\hline Sep. 95.4 b & Masculino & Adulto Maduro & $\mathrm{X}$ & $\mathrm{X}$ & - \\
\hline Sep. 95.5 a & Ind. & Lactente & - & $\mathrm{X}$ & - \\
\hline Sep. 95.5 b & Ind. & Lactente & $\mathrm{X}$ & $\mathrm{X}$ & $\mathrm{X}$ \\
\hline Sep. 95.6 & Masculino & Adulto Maduro & - & $\mathrm{X}$ & $\mathrm{X}$ \\
\hline Sep. 95.7 & Masculino & Adulto & - & $\mathrm{X}$ & - \\
\hline
\end{tabular}

\section{MÉTODOS}

Os métodos de análise dos três marcadores estão consolidados na literatura especializada e não envolveram o uso de técnicas destrutivas ${ }^{3}$. Todos os sinais de estresse (HP, CO e HLE) foram analisados macroscopicamente, com auxílio de uma lupa manual com aumento de 10 vezes e iluminação artificial. No caso das HLE, a iluminação foi utilizada tangencialmente às lesões. As sessões de análise foram de 50 minutos com intervalos de 10 minutos de descanso.

As análises de HP e CO seguiram critérios diagnósticos e formas de registro estabelecidos com base em StuartMacadam (1985) e Buikstra, Ubelaker (1994). Tais lesões foram analisadas quanto à localização (lado direito/esquerdo ou bilaterais) e quanto à atividade no momento da morte (lesões ativas, cicatrizadas ou em processo de cicatrização).

A CO é considerada na literatura como frequentemente, mas não necessariamente, bilateral. Dessa forma, quando a lesão estava presente somente em uma órbita, o indivíduo foi considerado analisável. Caso contrário, ele foi considerado não observável. Ainda que se tenha em conta que isso possa subestimar ligeiramente a análise, essa decisão foi tomada pela impossibilidade de garantir que um indivíduo que não possuísse a lesão na órbita presente, não possuísse lesão na órbita ausente.

A análise de HLE seguiu critérios diagnósticos e formas de registro estabelecidos com base na literatura publicada sobre o tema (BUIKSTRA, UBELAKER, 1994; FISCHER, 2012; GOODMAN et al., 1980; PRIMEAU et al., 2015). Porções dentárias muito alteradas por desgaste e cálculo dentário foram desconsideradas da análise e da quantificação, pois prejudicam a visualização e as análises das HLE. Desse modo, as prevalências de HLE em determinada faixa etária foram calculadas considerando-se apenas as porções dentárias correspondentes àquela faixa etária efetivamente analisada.

Apesar de todas as HLE observadas terem sido registradas, foram consideradas para os cálculos de prevalência apenas as hipoplasias sistêmicas, ou seja, presentes em pelo menos dois dentes na mesma faixa de intervalo etário. Para a dentição permanente foram consideradas as faixas etárias conforme ilustração na Figura 5. Para a dentição decídua, foi seguido o proposto em Fischer (2012) e foram consideradas três faixas etárias para cada dente, correspondentes aos terços oclusal, médio e distal da coroa.

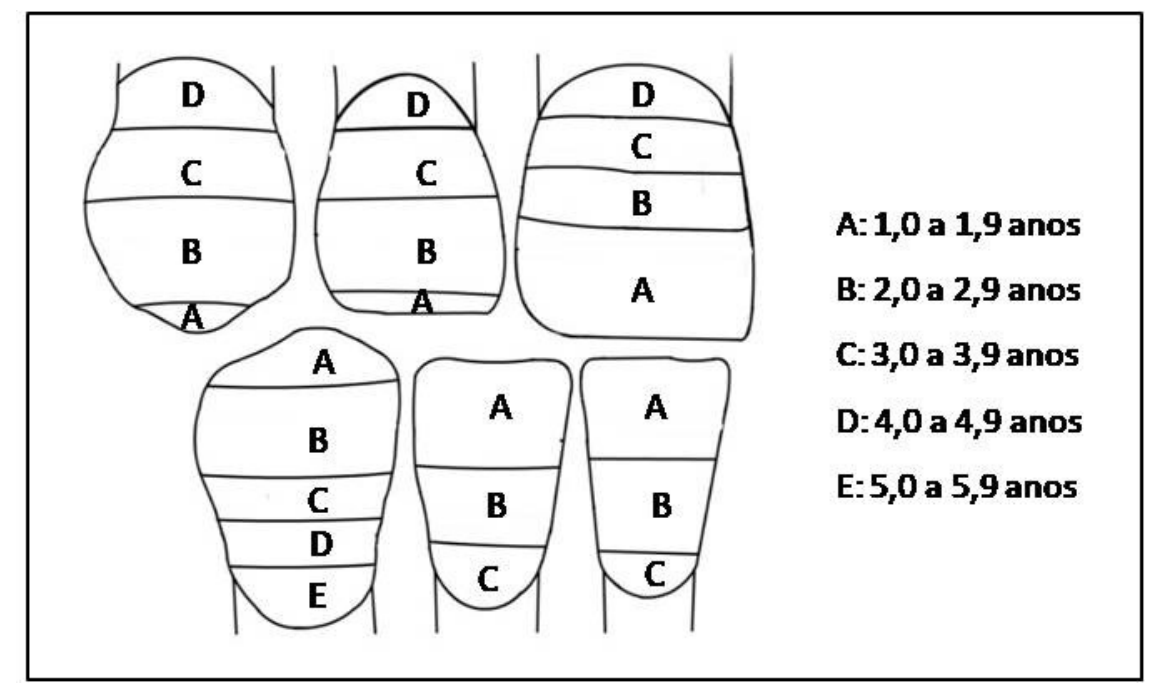

Figura 5: Ilustração das idades de crescimento estabelecidas para dentição permanente anterior 
No momento de efetuar o cálculo das prevalências por faixa etária, foi considerado um período etário ampliado com intervalo entre 0 e 2 anos, devido à baixa quantidade de indivíduos que puderam ser observados e a inexistência de indivíduos com HLE desenvolvidas nessas idades. As prevalências foram estatisticamente testadas utilizando o Teste de Fisher.

Os resultados obtidos para Içara foram considerados comparativamente aos resultados obtidos em análises feitas em outras séries esqueléticas oriundas de sambaquis, cujos resultados estão disponíveis na literatura (ex. MELLO e ALVIM, GOMES, 1989; MENDONÇA DE SOUZA, 1995; WESOLOWSKI, 2000; DEMAMANN, 2004; FISCHER, 2012).

\section{RESULTADOS}

As porosidades no crânio relacionadas à HP observadas na série de Içara-01 são, em sua maioria, pequenas, puntiformes e difusas, mas assumem aspecto serpenteado quando concentradas. As bossas parietais e a área de intersecção das suturas coronal e sagital foram as regiões com maior ocorrência. As lesões cicatrizadas (inativas) são rasas e apresentam bordos arredondados, com dispersão difusa na maioria dos indivíduos, embora em alguns casos tenham se apresentado em áreas de concentração (Figura 6). Já as lesões ativas são mais profundas, de maiores dimensões e bordos mais afiados, estando mais concentradas nas bossas parietais.

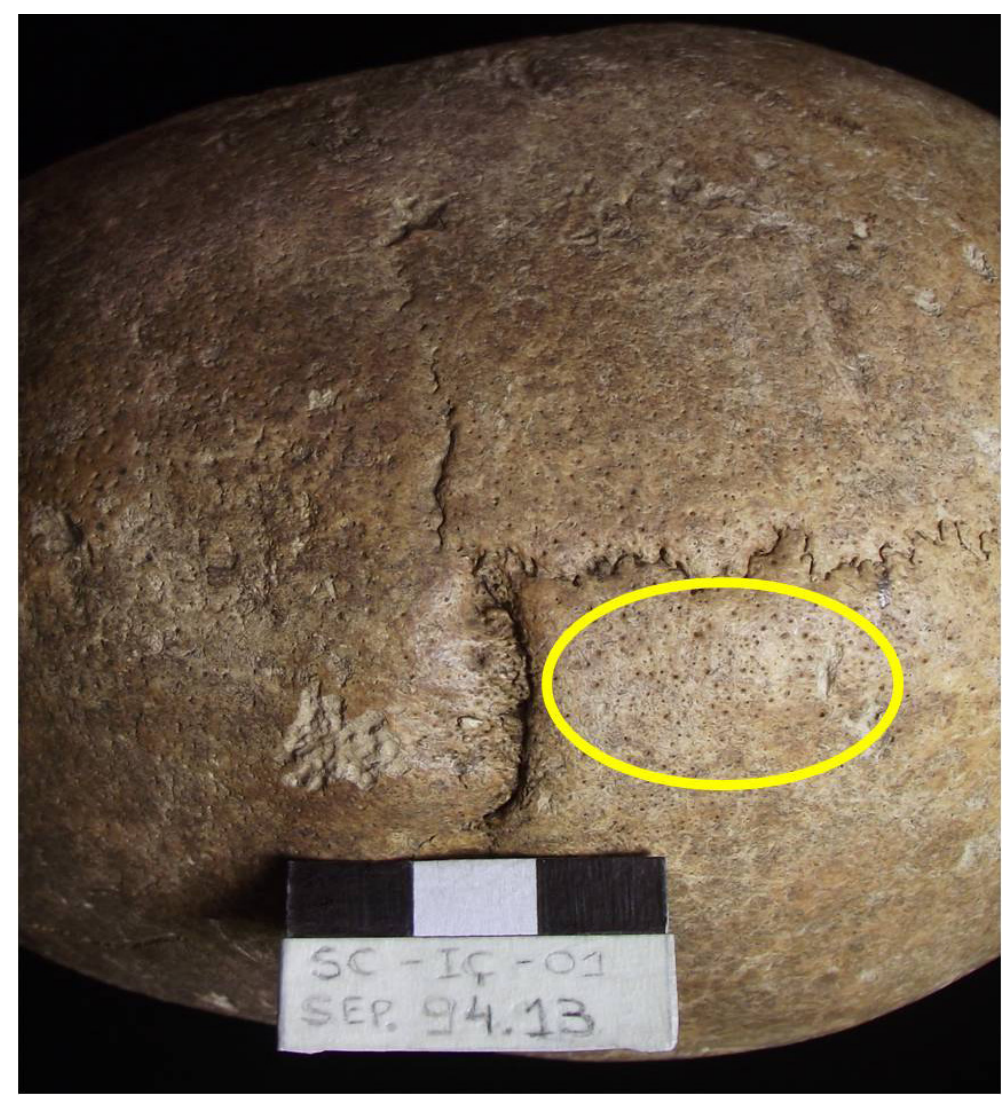

Figura 6: Hiperostose Porótica inativa em parietal direito (Foto: Marina Di Giusto)

As lesões relacionadas à $\mathrm{CO}$ apresentaram características muito semelhantes às das HP, arredondadas ou alongadas quando cicatrizadas e serpenteadas quando ativas, sendo em sua maioria bilaterais. Foram observadas lesões cicatrizadas e também ativas com evidência de cicatrização (Figura 7).

Em Içara-01 as prevalências de HP e CO foram altas, atingindo respectivamente $83 \%$ e 53\% dos indivíduos analisados, sem diferença estatisticamente significativa entre elas. Se comparados homens e mulheres, essas últimas apresentam prevalências de HP ligeiramente mais altas (respectivamente, 85\% e 100\%), quadro que se inverte quando se considera a CO (respectivamente $50 \%$ e $33 \%$ ). No entanto, mais uma vez as diferenças observadas não são estatisticamente significativas (Gráfico 1). 


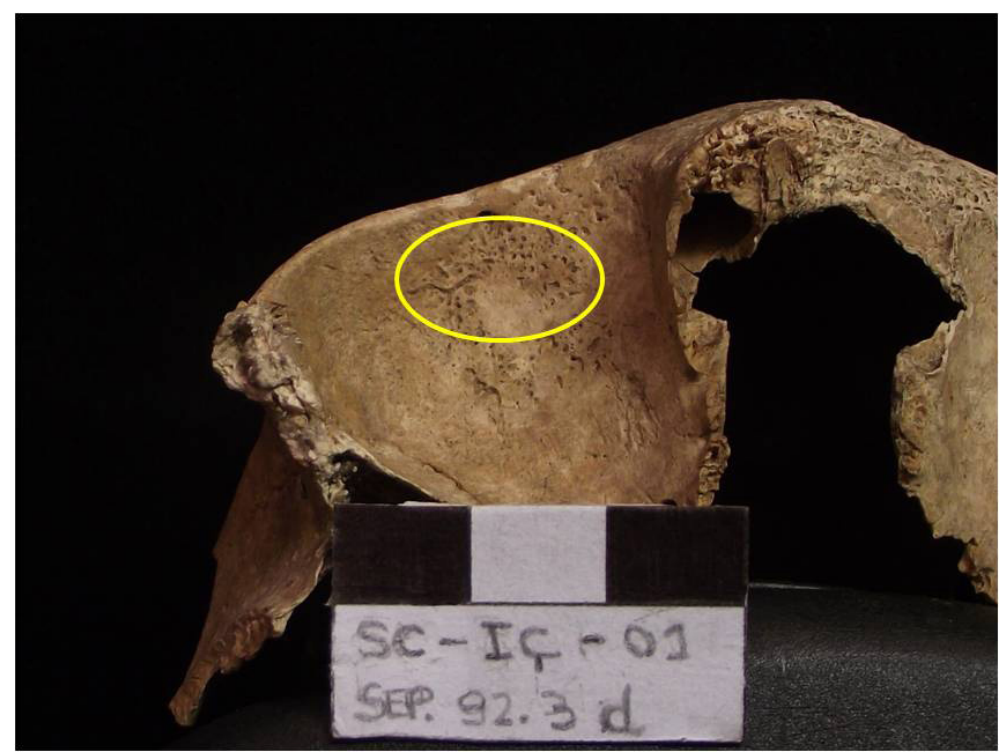

Figura 7: Cribra orbitalia ativa em órbita direita (Foto: Marina Di Giusto)

As análises sobre variações etárias nas prevalências de HP e CO ativas foram prejudicadas pela pequena quantidade de indivíduos passiveis de análise, e os dados disponíveis foram considerados de maneira exploratória. Dos 6 indivíduos subadultos disponíveis para análise de HP e CO em Içara-01, há três indivíduos com CO ativa com idades de 3 anos ( \pm 12 meses), 4 anos ( \pm 12 meses) e um jovem de aproximadamente 16 anos. Quanto aos adultos, foi observado um indivíduo feminino, com idade entre 26 a 34 anos, com lesões de HP ativas com sinais de cicatrização.

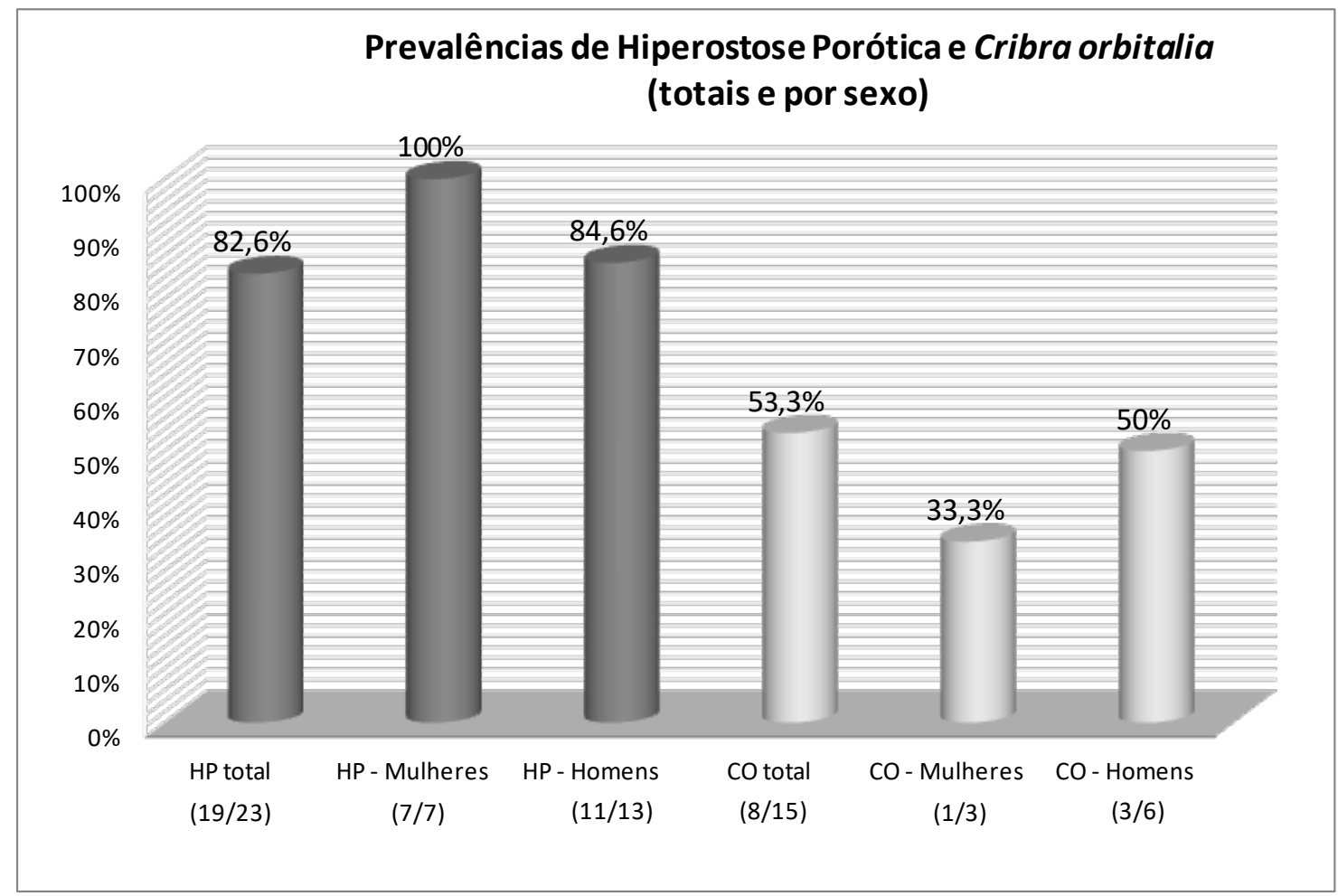

Gráfico 1: Prevalências de HP e CO observadas nos indivíduos de Içara-01. As frações abaixo das barras indicam, respectivamente, a quantidade de indivíduos que apresentam as lesões e a quantidade de indivíduos totais observáveis para cada classificação.

Dentre os indivíduos analisados para HLE, nenhum apresentou HLE sistêmica na dentição decídua, o que sugere condições de desenvolvimento estáveis, tanto intrauterina quanto nos primeiros seis meses de vida pós-natal, sem ocorrência de eventos de estresse que tenham levado a descontinuidades fisiológicas que resultariam na formação de HLE. Este quadro 
sugere que a saúde e nutrição maternas eram suficientes para manter condições adequadas para a formação do feto e para a amamentação. Além disso, sugere-se também uma boa capacidade de adaptação do recém-nascido ao meio e de cuidados parentais nos primeiros meses de vida.

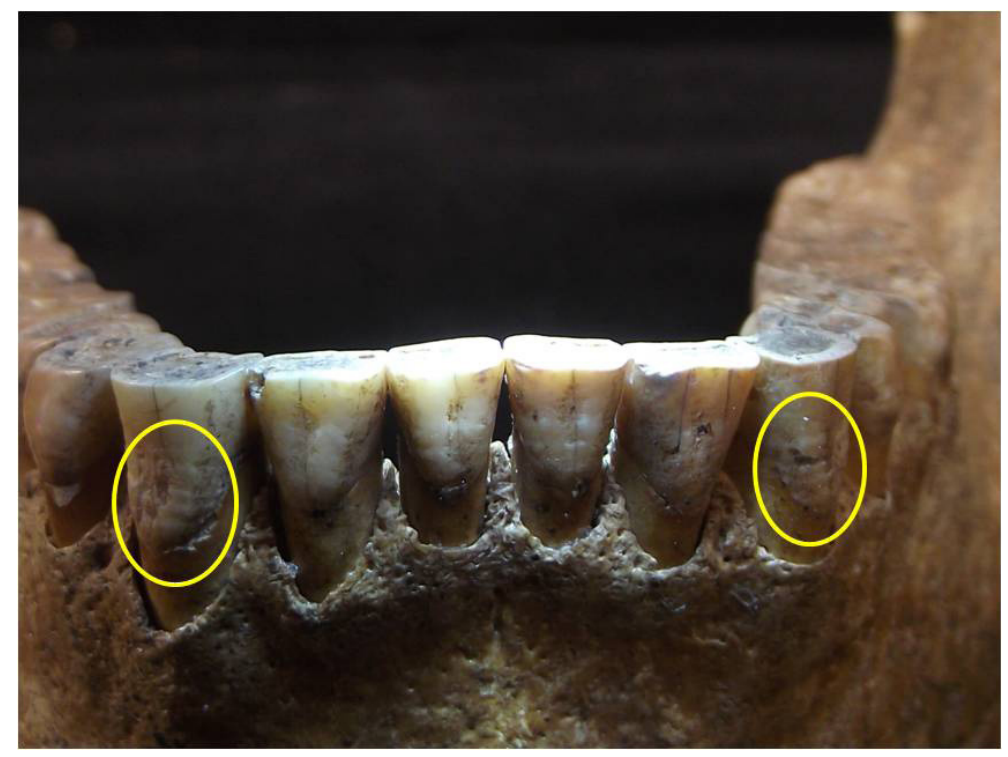

Figura 8: HLE em dentes anteriores inferiores - Sep. 95.1 (Foto: Marina Di Giusto)

Por outro lado, a prevalência total de HLE na dentição permanente é alta, com $85 \%$ dos indivíduos analisados apresentando pelo menos uma linha hipoplásica sistêmica. As mulheres apresentam prevalências ligeiramente mais baixas (75\%) que os homens (100\%). Em ambos os casos não houve diferença estatisticamente significativa. As linhas observadas são bem definidas, embora não sejam particularmente largas ou profundas (Figura 8).

O número de HLE sistêmicas apresentadas por um mesmo indivíduo sugere o número mínimo de vezes em que ele esteve submetido a eventos de estresse que provocaram parada de crescimento, o que pode ocorrer em uma única faixa etária ou em faixas etárias diferentes, ou seja, em um ou mais intervalos de idade. No caso da série de Içara-01 o mais comum é que os indivíduos apresentem duas linhas (sinalizando duas paradas de crescimento), condição encontrada em $31 \%$ dos indivíduos, semelhante às prevalências observadas para 3 e 4 linhas (sinalizando 3 e 4 paradas de crescimento observadas em $20 \%$ dos casos, respectivamente). Por outro lado, apenas uma minoria de indivíduos (8\%) apresentou apenas uma HLE sistêmica (somente uma parada de crescimento).

Esse quadro precisa ser ponderado pelo número de faixas etárias em que um mesmo individuo foi afetado e pelos eventos de estresse que resultaram em HLE, uma vez que um indivíduo ser afetado mais de uma vez em uma mesma faixa etária ou ser afetado ao longo de várias faixas (ou seja, ao longo de um período maior de tempo), significam padrões de estresse distintos. No caso de Içara-01, os dados indicam que os indivíduos foram afetados com maior freqüência em múltiplas faixas de idade, com a maioria tendo sido afetada em pelo menos duas faixas (38\%). Considerando-se qualitativamente e em conjunto o número de linhas e o número de faixas afetadas, os dados indicam que um indivíduo foi afetado mais de uma vez na mesma faixa etária e que dois indivíduos apresentaram eventos de estresse continuados ao longo de um intervalo etário prolongado (Gráfico 2).

Considerando a distribuição das hipoplasias segundo faixas de idade, o pico de ocorrência é entre 3-4 anos, período em que $85 \%$ dos indivíduos apresentam HLE, seguida pela faixa de 4-5 anos, na qual 61\% dos indivíduos apresenta HLE. As faixas que correspondem a idades mais tardias (5-6 anos) e mais precoces (2-3 anos) apresentaram frequências de indivíduos afetados por HLE de $33 \%$ e $38 \%$, respectivamente, o que para a faixa mais tardia é bastante elevado ${ }^{4}$. Embora tenham sido analisados dez indivíduos para o período de 0 a 2 anos, nenhum apresentou HLE sistêmica (Gráfico 3).

O intervalo de 5 a 6 anos de idade é considerado de baixo risco quanto à suscetibilidade ao estresse. Segundo a Organização Mundial da Saúde, o intervalo mais importante em que as crianças estão em maior risco de serem afetadas por fatores exógenos, tais como infecções, acidentes e má nutrição, é no intervalo entre 1 e 4 anos (WHO, 2015). 


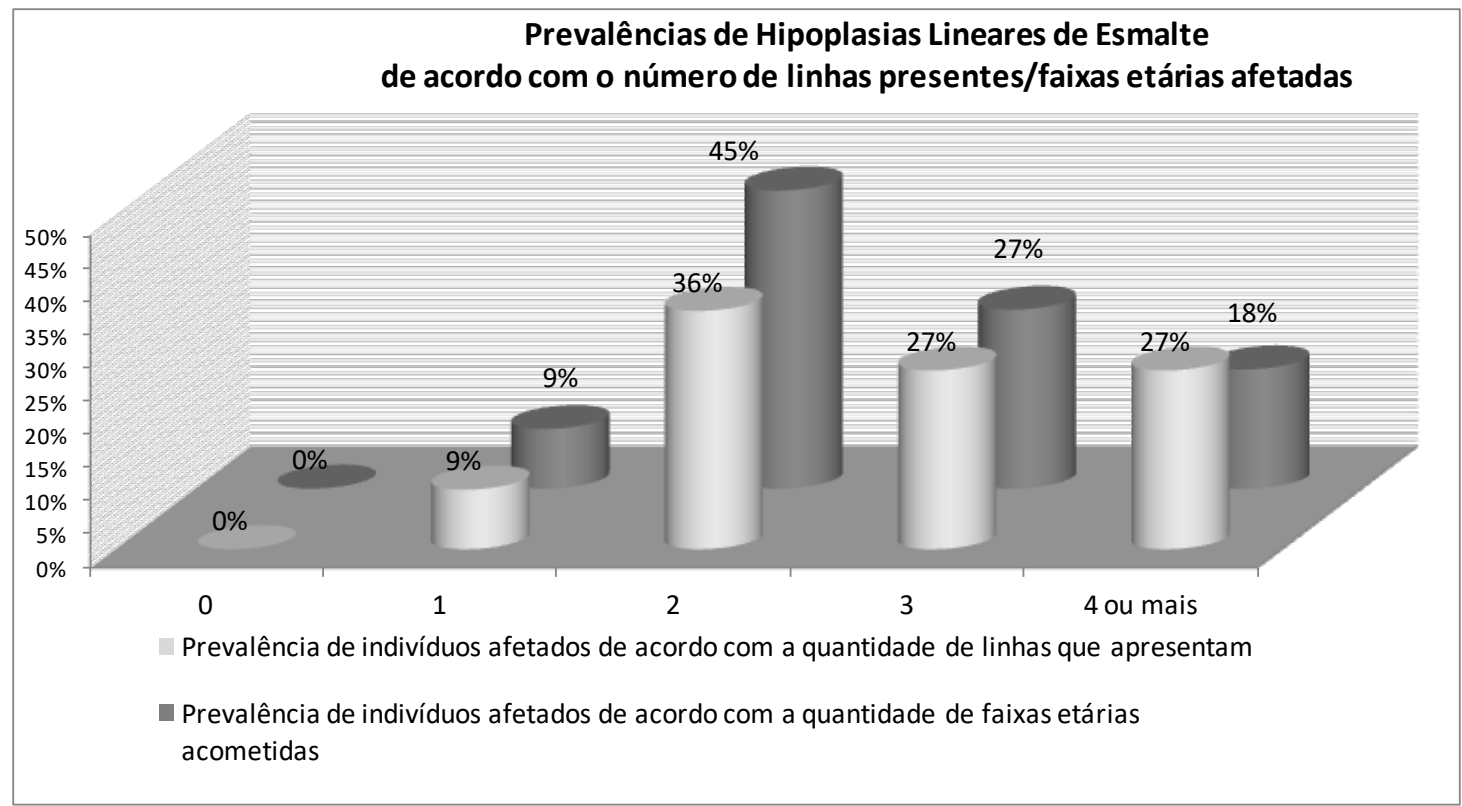

Gráfico 2: Prevalência de indivíduos de Içara-01 de acordo com o número de linhas de HLE presentes (colunas claras) e a quantidade de faixas etárias afetadas (colunas escuras).

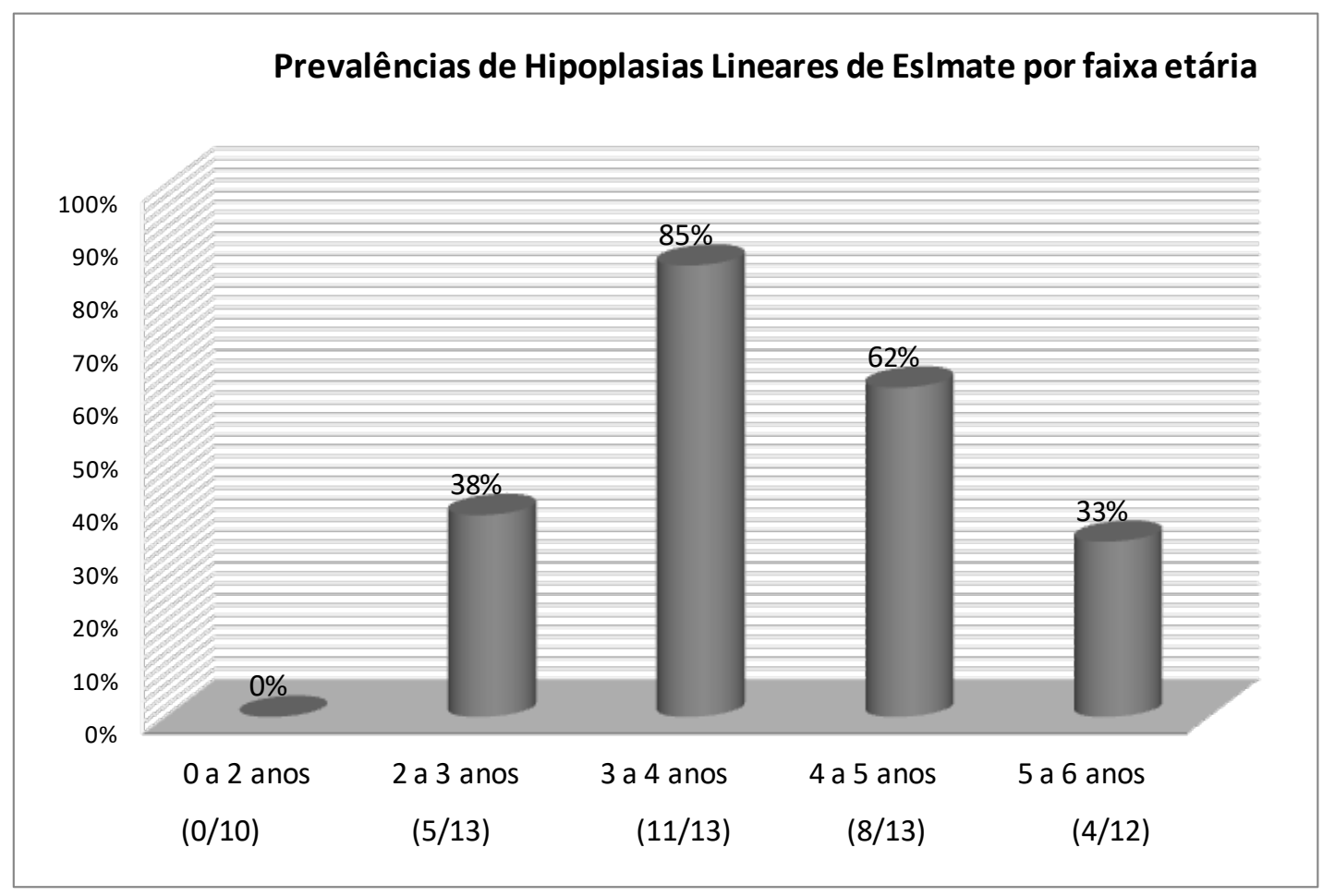

Gráfico 3: Prevalência de HLE por faixa etária. As frações abaixo das barras indicam, respectivamente, a quantidade de indivíduos que apresentam as lesões e a quantidade de indivíduos totais observáveis para cada faixa etária. 


\section{DISCUSSÃO}

Depois de quase 6.000 mil anos de ocupação sambaquieira, considerada muito estável em termos de cultura material (GASPAR et al., 2008; DeBLASIS, GASPAR, 2009; FISH et al., 2013), no litoral catarinense o quadro começa a mudar significativamente a partir de aproximadamente 1800 anos AP, quando começam a ser observadas mudanças no registro arqueológico em vários pontos da costa de Santa Catarina.

Nos onipresentes sambaquis, as conchas parecem perder importância como elemento construtivo, dando lugar a um substrato predominantemente constituído de sedimentos de origem mineral (areia), ossos de peixes e carvão, com uma quantidade de conchas muito menor (NISHIDA, 2007; KLÖKLER et al., 2010; VILLAGRAN, 2013; DeBLASIS et al., 2014).

No litoral sul-catarinense, em alguns casos estes depósitos dão continuidade à construção de alguns sambaquis (como no caso emblemático de Jabuticabeira II), sendo que em outros aparecem formando montículos que não se sobrepõe a qualquer sambaqui. De qualquer modo, estes depósitos mais recentes apresentam registro funerário, faunístico e artefatual semelhantes aos sambaquieiros (VILLAGRAN, 2013) e são denominados por alguns autores como "sambaquis tardios" (DeBLASIS et al., 2014) e por outros como "sítios mistos" ou "montículos ictiológicos" (VILLAGRAN, 2013). Nesse mesmo período ocorrem variações semelhantes também nas porções norte (Baía da Babitonga) e central (Ilha de Santa Catarina) do litoral catarinense, tais como aquelas vistas na camada superficial dos sambaquis Enseada I e Forte Marechal Luz (WESOLOWSKI, 2000) ou nos sítios Tapera e Base Aérea (BECK, 1972).

$\mathrm{O}$ aparecimento de cerâmicas associadas às tradições Taquara e Itararé, usualmente vinculadas a grupos Jê do planalto, constitui outro elemento da variação nesse momento. Apesar de presente desde pelo menos 1800 anos AP em vários pontos do litoral catarinense, se tornará efetivamente prevalente apenas cerca de 900-800 anos AP, quando aparecem sítios indubitavelmente identificados como associados a grupos Jê do planalto, como Galheta IV no município de Laguna (DEBLASIS et al., 2014).

A questão da chegada de populações do planalto ao litoral tem sido constantemente investigada na pesquisa arqueológica, levada a cabo na região desde a década de 1970. Os modelos mais antigos para explicar a presença de cerâmica Itararé-Taquara no litoral e as subsequentes mudanças que acabaram por levar à interrupção da construção de sambaquis, trazem consigo a idéia de substituição populacional completa de forma relativamente rápida, com a prevalência dos grupos horticultores do planalto prevalecendo sobre os sambaquieiros, que depois de 6000 anos de estabilidade desapareceriam completamente do registro arqueológico em menos de 1000 anos.

Mais recentemente, modelos alternativos têm surgido, sendo o trabalho de DeBlasis e colaboradores (2014) uma das primeiras tentativas de fazê-lo. Algumas mudanças fundamentais envolvem ideias como: (1) os processos de contato entre populações do planalto e do litoral foram distintos em regiões e épocas diferentes, (2) antes da chegada efetiva no litoral de contingentes populacionais importantes vindos do planalto, os contatos já existiam e podiam ser mediados por trocas de vários tipos, incluindo alimentos e pessoas. Essas ideias não aparecem de forma explicita e articuladas, mas estão subjacentes em vários trabalhos que vêm sendo desenvolvidos nos últimos quinze anos (ex. WESOLOWSKI, 2007; DeBLASIS et al., 2014).

É nesse contexto de mudança e "inovação" no registro arqueológico do litoral catarinense que se enquadra o sítio Içara-01, com datações que o colocam no mesmo período temporal que as ocupações mais recentes do sambaqui de Cabeçuda e de Jabuticabeira II (neste caso já na camada preta) (GIUSTO, 2017), ou ainda em período muito semelhante ao das ocupações recentes do sambaqui de Enseada I e Forte Marechal Luz (WESOLOWSKI et al., 2007) no litoral norte.

Içara-01 é entendido pelos pesquisadores que o tem estudado como um acampamento temporário de grupos Jê do planalto que estariam expandindo seu território para o litoral sem, no entanto, deixar o planalto. Dessa forma, esses grupos incursionariam à costa sazonalmente em busca de recursos costeiros de verão e para realizar os rituais funerários necessários (IZIDRO, 2001).

Sob essa hipótese e sob uma perspectiva teórica na qual o padrão de estresse refletiria aspectos do modo de vida dos grupos, o esperado seria encontrar padrões de HP, CO e HLE distintos entre a série esquelética de Içara-01 e séries esqueléticas sambaquieiras, em particular aquelas da região sul de Santa Catarina. Tal resultado seria mais evidente se for considerado que este grupo seria horticultor, que passaria o ano em duas condições ambientais e de moradia bastante distintas (planalto e litoral) e que teria um padrão de mobilidade que envolveria um deslocamento grande entre esses dois ambientes. 
As prevalências de HP e CO encontradas em Içara-01 são muito elevadas, estando coerentes com aquelas encontradas em grande parte dos grupos litorâneos do continente americano, incluindo grupos sambaquieiros, para as quais têm sido referidas prevalências superiores a 50\% (WALKER, 1986; MELLO e ALVIM, GOMES, 1989; MENDONÇA DE SOUZA, 1995; WESOLOWSKI, NEVES, 2002; BLOM et al., 2005; SUBY, 2014; GIUSTO, 2017).

Comparativamente, Walker (1986) indica prevalências muito mais baixas (em torno de 30\%) para grupos cuja dieta esteve baseada em milho, mesmo quadro encontrado por Mello e Alvim, Gomes e Uchôa (1991) e Wesolowski (2000), que referem prevalências mais baixas (entre $20 \%$ e $40 \%$ ) em séries oriundas de sítios litorâneos com impressiva quantidade de cerâmica, como Enseada I, Forte Marechal Luz e Itacoara.

Partindo do pressuposto de que em grupos costeiros americanos pré-coloniais a anemia ferropênica crônica é consequente de infecções e parasitoses (MELLO e ALVIM, GOMES, 1989; MELLO e ALVIM et al., 1991; MENDONÇA DE SOUZA, 1995; WESOLOWSKI, 2000; DEMAMANN, 2004; MENDONÇA DE SOUZA et al., 2009) e que pode ser representada pelos marcadores de $\mathrm{HP}$ e $\mathrm{CO}$, pode-se entender que esta condição configurar-se-ia como endêmica no grupo que ocupou Içara-01. Tal resultado está em conformidade com o que também é visto em sambaquis da região, como Jabuticabeira II e Cabeçuda, que apresentam prevalências de HP acima de 70\%, sem diferença estatística significativa em relação às prevalências observadas em Içara-01 (GIUSTO, 2017 para dados completos).

Tendo em vista que (1) a presença de HP e CO em adultos pode ser reflexo da condição anêmica na infância e (2) tanto mulheres quanto homens foram afetados de modo semelhante em Içara, é possível propor uma ausência de tratamentos socioculturais e de acesso à alimentação distintos entre meninas e meninos na infância. Este mesmo quadro é observado em séries sambaquieiras no litoral sul (GIUSTO, 2017) e no litoral norte de Santa Catarina (WESOLOWSKI, 2000).

Em relação às HLE, a prevalência de $85 \%$ encontrada é compatível com as verificadas em séries esqueléticas sambaquieiras do litoral norte e sul de Santa Catarina (WESOLOWSKI, NEVES, 2002; GIUSTO, 2017) e sugerem que as crianças estavam rotineiramente expostas a períodos de estresse fisiológico a partir do terceiro ano de vida, com maior risco entre 3 e 4 anos. A série esquelética de Içara-01, contemporânea às séries esqueléticas dos períodos de ocupação mais recentes de Jabuticabeira II e Cabeçuda, apresenta um comportamento muito semelhante a estas no que diz respeito à distribuição etária das HLE, que apresenta o pico de ocorrência entre 3 e 4 anos, mas com cerca de 33\% dos indivíduos afetados entre 5 e 6 anos (GIUSTO, 2017 para maiores informações comparativas). Esse pico de ocorrência no terceiro ano de vida é o mesmo padrão verificado em séries sambaquieiras do litoral norte, mas é distinto daquele verificado em séries oriundas de camadas que já apresentam cerâmica nessa mesma região (p.ex. Enseada I e Forte Marechal Luz), que apresentam pico de ocorrência mais tardio entre 4 e 6 anos (WESOLOWSKI, 2000; WESOLOWSKI, NEVES, 2002).

A existência de um indivíduo em Içara-01 portador do que entendemos hoje por necessidades especiais permite uma reflexão individualizada, que lança uma perspectiva particular sobre o quadro geral apresentado pelo grupo. Tratase de um indivíduo de sexo masculino, com idade estimada entre 35 e 49 anos e que apresenta um quadro de alterações congênitas compatíveis com Deficiência Focal Proximal do Fêmur (DFPF) ${ }^{5}$, as quais envolvem a má formação do fêmur e do acetábulo direitos. Nesse indivíduo também são encontradas alterações no rádio e na ulna esquerdos, em alguns ossos do carpo e tarso, e na patela, estando presente também fenda palatina (IZIDRO, 2001, MENDONÇA DE SOUZA, com. pess.). Essa é uma condição incapacitante que no mundo contemporâneo frequentemente leva ao uso de prótese. Com o comprometimento de sua capacidade de marcha e locomoção, seria necessário que esse indivíduo fosse carregado, que se locomovesse de modo a não envolver caminhada ou que utilizasse um dispositivo de auxílio (ex: muletas). Além disso, a fenda palatina provavelmente dificultou sua alimentação desde o período de aleitamento materno. Sua condição era evidente desde o nascimento, acentuando-se quando deveria começar a andar. Entretanto, apesar das dificuldades, esse indivíduo não foi removido da sociedade por qualquer mecanismo de controle cultural (como infanticídio ou exposição) nem foi a óbito por complicações associadas a má nutrição ou cuidados insuficientes, tendo sobrevivido até uma idade bastante avançada.

No que diz respeito à $\mathrm{HP}$ e CO, esse indivíduo apresenta o padrão observado para a maioria dos indivíduos analisados: HP cicatrizada, indicativa de anemia na infância, sem sinais de CO. Quanto à HLE, ela não pode ser avaliada devido ao alto desgaste dentário, que é compatível com o observado em outros indivíduos da série, indicando um padrão alimentar coerente com os dos demais adultos. 
Apesar dessa condição e dos problemas dela decorrentes, tais efeitos não parecem tê-lo feito particularmente mais suscetível do que outras crianças e adultos aos processos que afetavam o grupo como um todo. Tendo em vista as altas prevalências para HP em Içara, ao menos para a condição anêmica, ele apresenta um padrão semelhante ao restante do grupo, apesar de sua condição específica condicionar riscos individuais completamente distintos daqueles aos quais as demais crianças e adultos estavam sujeitas. Se por si só sua sobrevivência para além da quarta década de vida já sinaliza cuidado social do grupo para com ele, seu perfil de estresse, semelhante ao dos demais indivíduos, parece sugerir que foi cuidado com atenção pelo grupo.

\section{CONCLUSÃO}

No geral, os dados conjugados de HP, CO e HLE sugerem que os sepultados em Içara-01 foram afetados na infância por eventos estressores que acometeram a maioria das crianças de modo semelhante, em particular aqueles que levaram ao desenvolvimento de anemia, assim como ocorre nos sambaqui do litoral sul e norte de Santa Catarina. Entretanto, um pequeno grupo esteve sujeito a eventos de estresse por um período mais prolongado da infância (sinalizado pela frequência de HLE na faixa de 4-5 anos), aproximando-se, neste caso, do padrão que foi observado para a série esquelética mais recente de Jabuticabeira II (camada preta) (GIUSTO, 2017).

Do mesmo modo, admitindo-se que o pico de HLE esteja relacionado ao processo de desmame e aos riscos ocasionados pela transição alimentar e subsequente parada total do aleitamento materno (que expõe a criança a maiores riscos de contaminação alimentar e reduz a imunidade passiva resultante dos anticorpos ingeridos com o leite materno), o pico observado em Içara-01 indica a ocorrência de um padrão semelhante ao dos sambaquis e, ao mesmo tempo, diverso ao que é observado em séries relacionadas a grupos horticultores ou ainda a séries litorâneas mais recentes, associadas à presença de cerâmica Itararé-Taquara.

O quadro pintado pelos padrões de estresse fisiológicos aqui observados sugere que o grupo de Içara-01 provavelmente tinha uma relação mais próxima com o litoral do que apenas a prática de acampamentos temporários de verão, sendo possível que tivessem residência permanente no litoral, ou pelo menos, ali permanecessem por períodos mais prolongados do que aquele até agora cogitado. Esse quadro parece, sobretudo quando comparado com o que ocorre na ocupação mais recente de Jabuticabeira II (GIUSTO, 2017), falar a favor de modelos mais complexos de interação entre grupos Jê e sambaquieiros nesta região do litoral sul de Santa Catarina. Essa complexidade já vinha sendo indicada no âmbito da Bioarqueologia por trabalhos com foco na craniometria, como o de Hubbe e colaboradores (2003), que concluíram que os crânios masculinos de Içara estariam biologicamente mais associados aos grupos construtores dos grandes sambaquis do litoral sul, enquanto que os crânios femininos estariam associados a grupos ceramistas da tradição Itararé do litoral e interior. Esse resultado encontrou eco nas descobertas recentemente publicadas de pesquisa arqueogenética, cujos resultados demonstram uma relação genética bastante próxima entre indivíduos de Jabuticabeira II datados em torno dos 2000 anos e grupos Kaingang (POSTH et al., 2018).

Para completar e detalhar o quadro sobre o modo de vida do grupo de Içara-01, inclusive quanto à mobilidade e relação com outros grupos litorâneos, seria necessário mais estudos de marcadores de estresse e patologias ósseas e dentárias, análises isotópicas para Estrôncio, Carbono e Nitrogênio, além de análises arqueogenéticas.

Agradecimentos: Ao Pe. Pedro Ignácio Schmitz pela autorização de acesso à série esquelética de Içara. À Sheila Mendonça de Souza pela cessão de informação inédita sobre o indivíduo especial de Içara. 


\section{REFERÊNCIAS BIBLIOGRÁFICAS}

ANGEL, J. L. Porotic Hyperostosis, Anemias, Malarias and Marshes in the Prehistoric Eastern Mediterranean, Science, Vol. 153, pp.760$763,1966$.

ARMELAGOS, G. Bioarchaeology as Anthropology. Archaeological Papers of the American Anthropological Association, Vol. 13, Issue 01, pp. 27-40, 2003.

BECK, A. A Variação do Conteúdo Cultural dos Sambaquis do Litoral Sul de Santa Catarina. Tese (Doutorado), Faculdade de Filosofia, Letras e Ciências Humanas, Universidade de São Paulo, São Paulo, 1972.

BLOM, D.E.; BUIKSTRA, J.E.; KENG, L.; TOMCZAK, P.D.; SHOREMAN, E.; STEVENS-TUTTLE, D. Anemia and Childhood Mortality. Latitudinal Patterning Along the Coast of Pre-Columbian Peru. American Journal pf Physical Anthropology, ${ }^{\circ}$ 127, pp. 152-169, 2005.

BRITTON, H.; CANBY, J.; KOHLER, C. Iron Deficiency Anemia Producing Evidence of Marrow Hyperplasia in the Calvarium. Pediatrics, No 25 , pp.621-628, 1960.

BUIKSTRA, J.E. Preface. In: J.E. BUIKSTRA, L.A. BECK (orgs.), Bioarchaeology: The Contextual Analysis of Human Remains. Elsevier Inc, 2006.

BUIKSTRA, J.; UBELAKER, D.H. Standards for Data Collection From Human Skeletal Remains. Arkansas Archeological Survey Research Series, No 44, Fayetteville, Arkansas, 1994.

CARLSON, D.; ARMELAGOS, G.; GERVEN, D. Factors Influencing the Etiology of Cribra Orbitalia in Prehistoric Nubia. Journal of Human Evolution, № 3, pp. 405-410, 1974.

DeBLASIS, P.; GASPAR, M.D. Sambaquis do Sul Catarinense. Retrospectiva e Perspectivas de Dez Anos de Pesquisas. Especiaria, UESC, Vol. 11/12, pp. 20-30, 2009.

DeBLASIS, P.; FARIAS, D.S.; KNEIP, A. Velhas Tradições e Gente Nova no Pedaço: Perspectivas Longevas de Arquitetura Funerária na Paisagem do Litoral Sul Catarinense. Revista do Museu de Arqueologia e Etnologia, São Paulo, Vol. 24, pp. 109-136, 2014.

DEMAMANN, M.G.T. Estudos de Sinais de Anemia (Hiperostose Porótica e Cribra Orbitalia) nos Esqueletos Humanos de Içara, SC In: CONGRESSO DA SOCIEDADE DE ARQUEOLOGIA BRASILEIRA, XII, 2003, São Leopoldo. Anais do XII Congresso da Sociedade de Arqueologia Brasileira - Arqueologias da América Latina, 2004.

EL-NAJJAR, M.; LOZOFF, B.; RYAN, D. J. The Paleoepidemiology of Porotic Hyperostosis in the American Southwest. Radiological and Ecological Considerations. Science, Vol. 124, No 4, pp. 918-924, 1975.

EL-NAJJAR, M.; ROBERTSON, A. L. Spongy Bones in Prehistoric America. Science, Vol. 193, pp. 141-143, 1976.

FISH, P.R.; FISH, S.K.; DeBLASIS, P.; GASPAR, M.D. Monumental Shell Mounds as Persistent Places in Southern Coastal Brazil. In: THOMPSON, V.; WAGGONER, J. (orgs.). The Archaeology and Historical Ecology of Small Scale Economies. University Press of Florida, pp. 12-140, 2013.

FISHER, P.F. Os Moleques do Morro e os Moleques da Praia: Estresse e Mortalidade em um Sambaqui Fluvial (Moraes, Vale do Ribeira de Iguape, SP) e em um Sambaqui Litorâneo (Piaçaguera, Baixada Santista, SP). Dissertação (Mestrado em Arqueologia), Museu de Arqueologia e Etnologia, Universidade de São Paulo, São Paulo, 2012.

GASPAR, M.D.; DeBLASIS, P.; FISH, S.; FISH, P. Sambaqui (Shell Mound) Societies of Coastal Brazil. In: SILVERMAN, H.; ISBELL, W.H. (Org.), Handbook of South American Archaeology. New York, NY, Springer, pp. 319-335, 2008.

GIUSTO, M.N.D. Os sambaquieiros e os Outros: Estresse e Estilo de Vida na Perspectiva da Longa Duração - O caso do Litoral Sul de Santa Catarina. Dissertação (Mestrado em Arqueologia), Museu de Arqueologia e Etnologia, Universidade de São Paulo, São Paulo, 2017.

GOODMAN, A.H.; ARMELAGOS, G.J.; ROSE, J.C. Enamel Hypoplasias as Indicators of Stress in Three Prehistoric Populations from Illinois. Human Biology, Vol. 52, № 03, pp. 515-528, 1980. 
GOODMAN, A.H.; MARTIN, D.L.; ARMELAGOS, G.J. Indications of Stress from Bone and Teeth. In: Paleopathology at the Origins of Agriculture, Academic Press, Inc, 1984.

HASSET, B.R. Missing Defects? A Comparison of Microscopic and Macroscopic Approaches to Identifying Linear Enamel Hypoplasia. American Journal of Physical Anthropology, Vol. 153, pp. 463-472, 2014.

HUBBE, M.; NEVES, W.; SCHMITZ, P. I.; BERNARDO, D. Afinidades Morfológicas do Grupo Humano de Içara com outras Séries Esqueletais do sul do Brasil: Primeiros Resultados. In: Congresso da Sociedade Brasileira de Arqueologia XII, São Leopoldo. Anais do XII Congresso da Sociedade de Arqueologia Brasileira, São Leopoldo, 2003.

HUSS-ASHMORE, R. Introduction: Health and Lifestyle Transition. In: Health and Lifestyle Change. R. Huss-Ashmore, J. Schall, M. Hediger (orgs.). MASCA, Research Papers in Science amd Archaeology, Pennsylvania, Vol. 09, pp. 07-12, 1992.

IZIDRO, J. M. O Jazigo Funerário de Içara no Contexto Litorâneo Catarinense. Dissertação (Mestrado), Centro de Ciências Humanas, Universidade do Vale do rio dos Sinos, São Leopoldo, 2001.

LARSEN, C. S. Bioarchaeology: Interpreting Behavior from the Human Skeleton. Cambridge: Cambridge University Press, 1997.

LUNA, L.H. Alcances y Limitaciones del Concepto de Estrés en Bioarqueología. Antípoda, Vol. 03, pp. 255-279, 2006.

MARTIN, D.L.; GOODMAN, A.H.; ARMELAGOS, G.J. Skeletal Pathologies as Indicators of Quality and Quantity of Diet. In: R. GILBERT, J.H. MIELKE (orgs.), The Analysis of Prehistoric Diets. Academic Press, pp. 227-279, 1985.

MARTIN, S.A.; GUATELli-STEINBERG, D.; SCIULLI, P.W.; WALKER, P. Brief Communication: Comparison of Methods for Estimating Chronological Age at Linear Enamel Formation on Anterior Dentition. American Journal of Physical Anthropology, Vol. 135, pp. 362-365, 2008.

MELlO E ALVIM, M.C.; GOMES, J. C. Análise e Interpretação da Hiperostose Porótica em Crânios Humanos do Sambaqui de Cabeçuda (SC-Brasil). Revista de Pré-História, São Paulo, Nº 7, pp. 127-145, 1989.

MELlO E ALVIM, M.C.; GOMES, J.C.O.; UCHÔA, D.P.; Cribra Orbitalia e Lesões Cranianas Congêneres em Populações PréHistóricas da Costa Meridional do Brasil. Revista do Museu de Arqueologia e Etnologia, São Paulo, Vol. 01, pp. 21-53, 1991.

MENDONÇA DE SOUZA, S.M.F. Estresse, Doença e Adaptabilidade: Estudo Comparativo de Dois Grupos Pré-Históricos em Perspectiva Biocultural. Tese (Doutorado em Saúde Pública), Escola Nacional de Saúde Pública, FIOCRUZ, Rio de Janeiro, 1995.

MENDONÇA DE SOUZA, S.M.F. Anemia e Adaptabilidade em um Grupo Costeiro Pré-Histórico: Uma Hipótese Patocenótica. In: TENÓRIO, M.C. (org.). Pré-História da Terra Brasilis. Ed. UFRJ, Rio de Janeiro, pp. 171-188, 1999.

MENDONÇA DE SOUZA, S.M.F. Bioarchaeology in Brazil. In: O’DONNABHAIN, B.; LOZADA CERNA, M.C. (Org.). Archaeological Human Remains: Global Perspectives. 1ed.: Springer eBooks, v. 1, p. 25-45, 2014.

MENDONÇA DE SOUZA, S.M.F.; RODRIGUES-CARVALHO, C. Uso de Adornos Labiais pelo Construtoes do Sambaqui de Cabeçuda (SC). Uma Hipótese Baseada no Perfil Dento-Patológico. Revista de Arqueologia, São Paulo, No 11, pp. 33-46, 1998.

MENSFORTH, R.P.; LOVEJOY, C.O.; LALLO, J.W.; ARMELAGOS, G. The Role of Constitutional Factors, diet and Infectious Disease in the Etiology of Porotic Hyperostosis and Periosteal Reactions in Prehistoric Infants and Children. Medical Anthropology, Vol. 02, pp. 01-59, 1978.

MOREIRA, A.S.; SILVA, R.A.A. Anemia Ferropriva em Portadores de Anemia Falciforme: A Importância de se Avaliar o Estado Nutricional do Ferro. Revista de Ciências Médicas e Biológicas, Salvador, BA, Vol. 13, No. 02, pp. 236-241, 2014.

MOSELEY, J.E. The Paleopathological Riddle of Symmetrical Osteoporosis. The American Journal of Roentgenology, Radium Therapy, and Nuclear Medicine, Vol. 95, No 01, pp, 135-142, 1965.

OKUMURA, M.M.; EGGERS, S. The People of Jabuticabeira II: Reconstruction of the Way of Life in a Brazilian Shellmound. Journal of Comparative Human Biology, № 55, pp. 263-281, 2005.

OKUMURA, M.M.; EGGERS, S. O que a Biologia Não Explica: Grupos de Afinidade no Sambaqui Jabuticabeira II. Revista do Museu de Arqueologia e Etnologia, São Paulo, Vol. 22, p. 191, 2012. 
PEZO-LANFRANCO, L.; DeBLASIS, P.; EGGERS, S. Weaning Process and Subadult Diets in a Monumental Brazilian Shellmound. Journal of Archaeological Science: Reports. 10 mai. 2018.

POSTH, C.N.; LAZARIDIS, N.; SKOGLUND, I.; MALLICK, P.; LAMNIDIS, S.; ROHLAND, T.C.; NÄGELE, N.; ADAMSKI, K.; BERTOLINI, N.; BROOMANDKHOSHBACHT, E.; COOPER, N.; CUlLETON, A.; FERRAZ, B.J.; FERRY, T.; FURTWÄNGLER, M.; HAAK, A.; HARKINS, W.; HARPER, K.; HÜNEMEIER, T.K.; LAWSON, T.; LLAMAS, NA.M.; MICHEL, B.; NELSON, M.; OPPENHEIMER, E. et al. Reconstructing the Deep Population History of Central and South America. CELL, v. 175, p. 1185, 2018.

PRIMEAU, C.; ARGE, S. O.; BOYER, C.; LYNNERUP, N. A Test of Inter - and Intra - Observer Error for an Atlas Method of Combined Histological Data for the Evaluation of Enamel Hypoplasia. Journal of Archaeological Science, Reports, Vol. 02, pp. 384-388, 2015.

REID, D.J.; DEAN, M.C. Brief Communication: The Timing of Linear Hypoplasias on Human Anterior Teeth. American Journal of Physical Anthropology, Vol. 113, pp. 135-139, 2000.

RITZMAN, T.B.; BAKER, A.J.; SCHWARTZ, G.T. A Fine Line: A Comparison of Methods for Estimating Ages of Linear Enamel Hypoplasia Formation. American Journal of Physical Anthropology, Vol. 135, pp. 348-361. 2008.

ROSA, A. O. Composição e Diversidade da Arqueofauna dos Sítios de Içara: SC-IÇ-01 e SC-IÇ-06. Pesquisas, Antropologia, Vol. 63, pp. 33-54, 2006.

SCHMITZ, P.I. Acampamentos Litorâneos em Içara, SC. Um Exercício em Padrão de Assentamento. CLIO, Série Arqueológica, Vol. 11, pp. 99-118, 1996.

SCHMITZ, P.I. Continuidade e Mudança no Litoral de Santa Catarina. Revista do Museu de Arqueologia e Etnologia, São Paulo, Vol. 8, pp. 25-31, 1998.

SCHMITZ, P.I.; ROSA, A.O.; IZIDRO, J.M.; HAUBERT, F.; KREVER, M.L.B.; BITENCOURT, A.L.V.; ROGGE, J.H.; BEBER, M.V. Içara: Um Jazigo Mortuário no Litoral de Santa Catarina. Pesquisas, Antropologia. Instituto Anchietano de Pesquisas, São Leopoldo-RS, No $55,1999$.

STECKEL, R.; SCIULLI, P.; ROSE, J. A Health Index From Skeletal Remains. In: STECKEL, R.H.; ROSE, J.C. (orgs.). The Backbone of History: Health and Nutrition in the Western Hemisphere. Cambridge University Press, UK, 2002, pp. 61-93, 2002.

STUART-MACADAM, P. Porotic hyperostosis: Representative of a childhood condition. American Journal of Physical Anthropology, $\mathrm{N}^{\circ}$ 66, Vol. 4, pp. 391-398, 1985.

STUART-MACADAM, P. Porotic hyperostosis: A new perspective. American Journal of Physical Anthropology, No 87, Vol. 1, pp. 39-47, 1992.

SUBY, J.A. Porotic hyperostosis and cribra orbitalia in human remains from southern Patagonia. Anthropological Science, Vol. 122, N 02, pp. 69-79, 2014.

VILLAGRAN, X. O que sabemos dos grupos construtores de sambaquis? Breve Revisão da Arqueologia da Costa Sudeste do Brasil, dos Primeiros Sambaquis até a Chegada da Cerâmica Jê. Revista do Museu de Arqueologia e Etnologia, São Paulo, Vol. 23, pp. 139-154, 2013.

WALKER, P.L. Porotic Hyperostosis in a Marine-Dependent California Indian Population. American Journal of Physical Anthropology, No 69, pp. 345-354, 1986.

WALKER, P.L.; BATHURST, R.; ROCHMAN, R.; GJERDRUM, T.; ANDRUSHKO, V.A. The Causes of Porotic Hyperostosis and Cribra Orbitalia: A Reappraisal of the Iron-Deficiency-Anemia Hypothesis. American Journal of Physical Anthopology, No 139, pp. 109-125, 2009

WESOLOWSKI, V. A prática da horticultura entre os construtores de sambaquis e acampamentos litorâneos da região da Baía de São Francisco: Uma abordagem Bio-Antropológica. Dissertação (Mestrado em Ciência Social), Faculdade de Filosofia, Letras e Ciências Humanas, Universidade de São Paulo, São Paulo, 2000. 
WESOlOWSKI, V. Cáries, Desgastes, Cálculos Dentários e Micro-Resíduos da Dieta entre Grupos Pré-Históricos do Litoral Norte de Santa Catarina: É Possível Comer Amido e Não ter Cárie? Tese (Doutorado em Saúde Pública), Escola Nacional de Saúde Pública, Fundação Oswaldo Cruz, Rio de Janeiro, 2007.

WESOLOWSKI, V.; NEVES, W. Variabilidade de Subsistência Entre os Grupos Costeiros Pré-Históricos do Litoral Norte de Santa Catarina, Brasil. Anais do XI Congresso da Sociedade de Arqueologia Brasileira, Rio de Janeiro, 2001.

WESOLOWSKI, V.; MENDONÇA DE SOUZA, S.; REINHARD, K.; CECCANTINI, G. Grânulos de Amido e Fitólitos em Cálculos Dentários Humanos: Contribuição ao Estudo do Modo de Vida e Subsistência de Grupos Sambaquianos do Litoral Sul do Brasil. Revista do Museu de Arqueologia e Etnologia, São Paulo, Vol. 17, pp.191-210, 2007.

WHITE, T.; FOLKANS, P. The Human Bone Manual. Elsevier Academic Press, 2005.

ZUCKERMAN, M.; GAROFAlO, E.; FROHLICH, B.; ORTNER, D. Anemia or Scurvy: A Pilot Study on Differential Diagnosis of Porous and Hyperostosis Lesions Using Differential Cranial Vault Thickness in Subadult Humans. International Journal of Paleopathology, $\mathrm{N}^{\mathrm{o}}$ 05, pp. 27-33, 2014. 